\title{
Casos fatales de infección por adenovirus
}

\author{
M.C. Elba Wu H. ${ }^{1}$; M.C. Virginia Martínez C. ${ }^{2}$; M.C. Ana Marja Alvarez . $^{3}$; \\ M.C. Carmen Larrañaga L. ${ }^{1}$; M.C. Hamilton Vela C. ${ }^{2}$
}

\section{Fatal adenovirus infections in infants and children}

\begin{abstract}
Sixteen fatal cases of adenovirus infection in infants (n:10 aged 1 to $<12$ months) and children (n:6 aged 1 to $3,8,12$ years) are reported. Diagnosis were confirmed by direct viral isolation, viral immunofluorescence or both in 15 patients, and by autopsy in 12 of them, including one without positive virological workup. Evidence of multisystemic compromise, particulary that of severe lower respiratory tract infection was observed and lead to death by acute respiratory failure in all cases. White blood cell counts and erythrocyte sedimentation rate did not help to label initially the etiology as either viral or bacterial. Chest roentgenograms showed pulmonary overinflation and evidence of pneumonitis as well as ex tensive and rapidly progresive lung opacifications. Most prominent pathologic findings were necrotizing bronchitis, bronchiolitis and broncopneumonia. Several cells containing typical intranuclear inclusion bodies were documented in ten cases and pneumonitis was the only finding in two. Hepatic fat infiltration and lymphocitic depletion of thymus, spleen and lymphatic nodes occurred in all cases. The need of rapid diagnostic tools to avoid nosocomial spread of this kind of infections with such serious consequences is stressed.
\end{abstract}

(Key words: pneumonia viral, adenovìus, fatal lower respiratory tract infections.)

La infección por adenovirus (Ad) ocurre en 2 a $24 \%$ de las enfermedades respiratorias virales en niños, encontrándose las incidencias mayores en niños hospitalizados por infección respiratoria aguda (IRA) baja ${ }^{1-11}$.

Existe amplia variación en el espectro clínico y severidad de las infecciones por Ad. Entre los factores de riesgo destacan el serotipo infectante $\mathrm{y}$ ciertas condiciones del huésped. Se ha descrito compromiso severo del tracto respiratorio inferior en infecciones por Ad especialmente con los serotipos 3,7 y 21 y entre los tres y ocho meses de edad. Otros factores del huésped que favorecerian una evolución más severa son los antecedentes 0 la concomitancia con otras enfermedades virales (p. ej., sarampión, influenza), desnutrición (lo que no se ha demostrado en todos los trabajos) e inmunodepresión producida por enfermedades o drogas ( $p$. ej., corticoides) $)^{1-3,9-10,12-21}$.

1. Departamento de Pediatría y Cirugia Infantil, Escuela de Medicina Occidente, Facultad de Medicina, Universidad de Chile.

2. Servicio de Anatomía Patológica, Hospital San Juan de Dios, Area de Salud Metropolitano Occidente, Ministerio de Sahud.

3. Servicio de Pediatría y Cirugía Infantil, Hospital San Juan de Dios, Area de Salud Metropolitano Occidente, Miristerio de Salud.
Los Ad, si bien constituyen la tercera causa de IRA baja viral en el menor de dos años, ad. quieren real importancia por la mayor letalidad $y$ las graves secuelas que producen, como bronquiectasias, bronquitis obstructiva, pulmón hiperlúcido, derivadas de las severas alteraciones anatomopatológicas que causan en el aparato respiratorio. A diferencia de otros virus capaces de producir sólo infección respiratoria, los Ad comprometen, además, con cierta frecuencia, otros órganos y son causantes incluso de falla multisistémica ${ }^{1-1} 1,17,18,21-40$

A continuación se describen las caracteristicas clínicas, de laboratorio, radiológicas y anatomopatológicas de dieciséis niños que fallecieron por IRA baja causada por Ad, demostrada por exámenes virológicos, hallazgos anatonropatológicos, o ambos.

\section{PACIENTES Y METODOS}

Se presentan dieciséis casos que fueron hospitalizados en el servicio de pediatría del Hospital San Juan de Dios, en Santiago de Chile, $y$ fallecieron a causa de IRA baja por Ad. Seis casos fueron esporádicos, entre 1983 y 1987; los diez restantes ocurrjeron en forma epidémica entre los meses de agosto y noviembre de 1988 .

En todos los niños se hizo estudio clínico deta. llado, $y$ exámenes de laboratorio que incluyeron hemograma, velocidad de eritrosedimentación (VHS), gases 
arteriales, cultivos bacteriológtcos y radiografías de tórax. En quince niños \& realizaron investigaciones virológicas, en doce por métodos de aislamiento (n:12), detección de antígenos (n:5) y serología (n:3), mientras aún vivian; después de morir, en ocho, mediante aislamiento y detección de antígenos. Las dos primeras técnicas se efectuaron en muestras de aspirado nasofaríngeo o de pulmón, seguín si fueron obtenidas en vida o durante la necropsia. El aislamiento se efectuó en células HEp2 y fibroblastos de pulmón humano fetal y los antigenos virales fueron detectados por inmunofluorescencia indirecta (IFI). El estudio de anticuerpos se realizó en dos muestras de suero tomadas con intervalos de 15 a 21 días. Se consideró que la identificación viral era positiva cuando el virus se detectó por aislamiento, presencia de antígeno o serología positiva. Esta illtima se consideró positiva cuando hubo seroconversión o alza del título de anticuerpos de cuatro o más veces entre el suero de fase aguda y el de convalecencia.

El estudio anatomopatológico se realizó en doce de los dieciséis casos e incluyó examen macroscópico e histopatológico.

\section{RESULTADOS}

La edad de estos niños al fallecer variaba entre un mes y 3 años 8 meses (10 menores de un año, 5 entre 1 y 2 años y un preescolar); catorce eran de sexo masculino, el estado de nutrición fue eutrofia en once y desnutrición grado I en los restantes.

Entre los antecedentes mórbidos relacionados destacaron hospitalizaciones previas por bronconeumonía (BN) o neumonitis $(\mathrm{N})$ en ocho pacientes y control ambulatorio por síndrome bronquial obstructivo (SBO) recidivante en siete enfermos. En la enfermedad actual había antece. dentes de exantema maculopapular eritematoso en cinco niños hospitalizados en 1988 (exantema morbiliforme considerado como sarampionoso en tres y puntiforme atribuido a la infección por Ad en dos), uso de corticoides días antes de la hospitalización en diez casos y contacto con pacientes infectados con Ad en cinco. La duración previa de la enfermedad fue variable, fluctuando entre 2 y 7 días en los casos con inicio extrahospitalario, pero fue difícil de precisar en los de origen intrahospitalario, ya que sus manifestaciones se superpusieron con las de la enfermedad que causó la hospitalización. En todos los enfermos el motivo de ingreso o traslado a la unidad de infecciosos fue afección respiratoria grave. Se plantearon los diagnósticos de SBO en seis nifros, $N$ intersticial en tres y $\mathrm{BN}$ en doce, en dos de ellos asociados con sarampión.
Las manifestaciones clínicas fueron múltiples. Las más relevantes eran fiebre mantenida de tipo séptico, en todos los casos; edema predominantemente de extremidades en nueve enfermos, en cinco de los cuales se detectó hipoproteinemia; compromiso respiratorio severo en todos los pacientes, caracterizado por polipnea, ałęteo nasal, retracción subcostal, espiración prolongada y signos auscultatorios de obstrucción y condensación; hepatomegalia sin características especiales, palpable en todos los casos 2 a 3 días antes de fallecer; manifestaciones gastrointestinales como diarrea en nueve enfermos, dos de los cuales se complicaron de hemorragia digestiva; compromiso del sistema nervioso central (SNC) en tres nifios, evidente en dos como síndrome convulsivo (uno de ellos con alteraciones quimicocitológicas del líquido cefalorraquídeo sugerentes de encefalitis) e interpretado en el tercero como posible síndrome de Reye; finalmente, se observó exantema puntiforme-petequial, del tipo que ha sido descrito en infecciones por $\mathrm{Ad}$, en dos ${ }^{1,2,32}$.

Los exámenes de laboratorio mostraron hipoxemia arterial mantenida $\left(\mathrm{pO}_{2}\right.$ menor de 60 mmHg) refractaria a $\mathrm{FiO}_{2}$ mayores de $40 \%$, e hipercapria en las etapas terminales. El recuento de leucocitos en la sangre periférica era nomal en siete casos, aumentado en seis y había leucopenia en tres; desviación a izquierda en siete. La VHS estaba entre 14 y $85 \mathrm{~mm} \cdot \mathrm{h}$. En ninguno de los niños se efectuó estudio inmunológico.

La radiografia de tórax mostró en la mayoría de los casos imágenes intersticiales confluentes y de relleno alveolar, bilaterales, con hiperinsuflación pulmonar importante, siendo la característica principal la rápida extensión del compromiso pulmonar, con opacificación de extensas zonas, en algunos casos en el curso de horas, concordante con la acentuación de la insuficiencia respiratoria del paciente (figuras $1 \mathrm{a}, \mathrm{b}$ y c).

El tratamiento se hizo con antibióticos en casi todos los enfermos, por la evolución de tipo séptico, con esquemas para neumopatía severa basados en la sensibilidad de los gérmenes más frecuentes para cada edad en ese tipo de afecciones. Se emplearon también broncodilatadores beta-2-adrenérgicos por vía oral 0 en nebulizaciones y corticoides por vía parenteral en nifios en que la magnitud de la obstrucción lo requirió. Desde su ingreso, a los pacientes se les aportó oxígeno según sus requerimientos; durante la evolución fue necesario recurrir a ventilación 


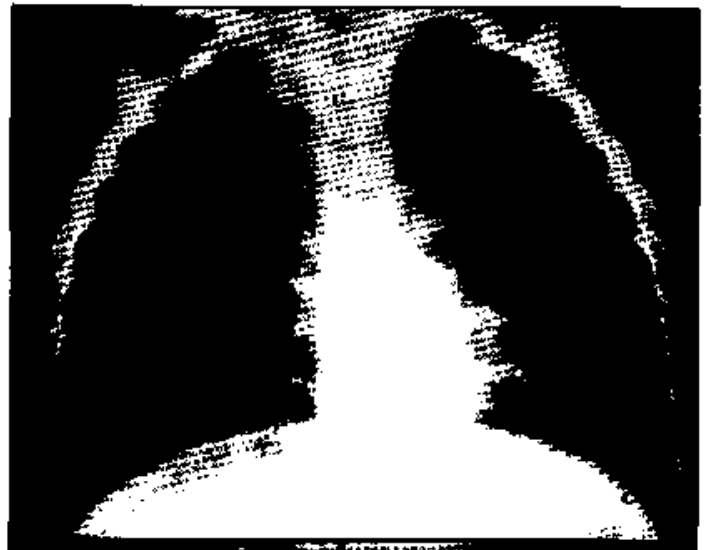

mecánica en 14 de ellos, sin obtenerse respuesta favorable.

Se detectó Ad en trece de los quince casos con estudio virológico. En vivo, en doce; mediante aislamiento, en 6; por inmunofluorescencia, en uno, y por más de una técrica, en 5 pacientes. En 5 casos el virus se identificó después de la muerte nediante aislamiento. Cuatro en los Ad detectados en muestras de autopsia fueron aislados de casos ya diagnosticados en vivo, y uno, de un ninto sin estudio etiológico previo. Los exámenes bacteriológicos fueron negativos.

Como los hallazgos morfológicos de los casos epidémicos fueron similares a los de los esporá. dicos en los 12 niños sometidos a autopsia, aquellos se describen en conjunto. Las lesiones pulmonares fueron relevantes en todos ellos. Habia también lesiones en otros parénquimas, como consecuencia de la infección viral, la hipoxia y el choque. Se observó, además, una afección incidental en un caso.

Patología pulmonar. En diez pacientes se desarrolló la forma clásica đe neumonía por $\mathrm{Ad}^{22,24}$, con descamación del epitelio alveolar y reacción inflamatoria mononuclear, siendo el compromiso pulmonar extenso, de por lo menos tres lóbulos pulmonares y con frecuencia de todos ellos (figuras 2 y 3). El peso pulmonar era entre dos $y$ cinco veces mayor que el correspondiente a la edad. En las áreas de consolidaciôn neumónica habia necrosis, hemorragias, edema y abundante infiltrado inflamatorio de predominio mononu. clear, numerosos macrófagos y ocasionales neutrófilos. En todos los casos se identificaron, en las células epiteliales alveolares y bron. quiolares, los dos tipos de inclusiones intranucleares características que representan diferentes etapas de células infectadas por Ad: células borrosas y las células con inclusiones intranucleares. En nueve niffos esas células fueron visibles en gran número; en cinco de estos casos se demos. tró intensa actjvidad regenerativa del epitelio bronquial y bronquiolar, con hiperplasia severa y metaplasia escamosa. En nueve se identificó, además, en las áreas no comprometidas por el proceso neumónico, manifestaciones propias del llamado pulmón húmedo o de choque: edema, hiperemia, hemorragias y membranas hialinas. Llamó la atención en el paciente preescolar el desarrollo de numerosos focos de bronquiolitis obliterativa y la organización parcial del exudado alveolar. Este mismo niño y uno de los lactantes mayores presentaron, además, células gigantes casi en su totalidad ambos campos pulmonares, borrando contornos diafragmáticos y de la silueta cardíace. 


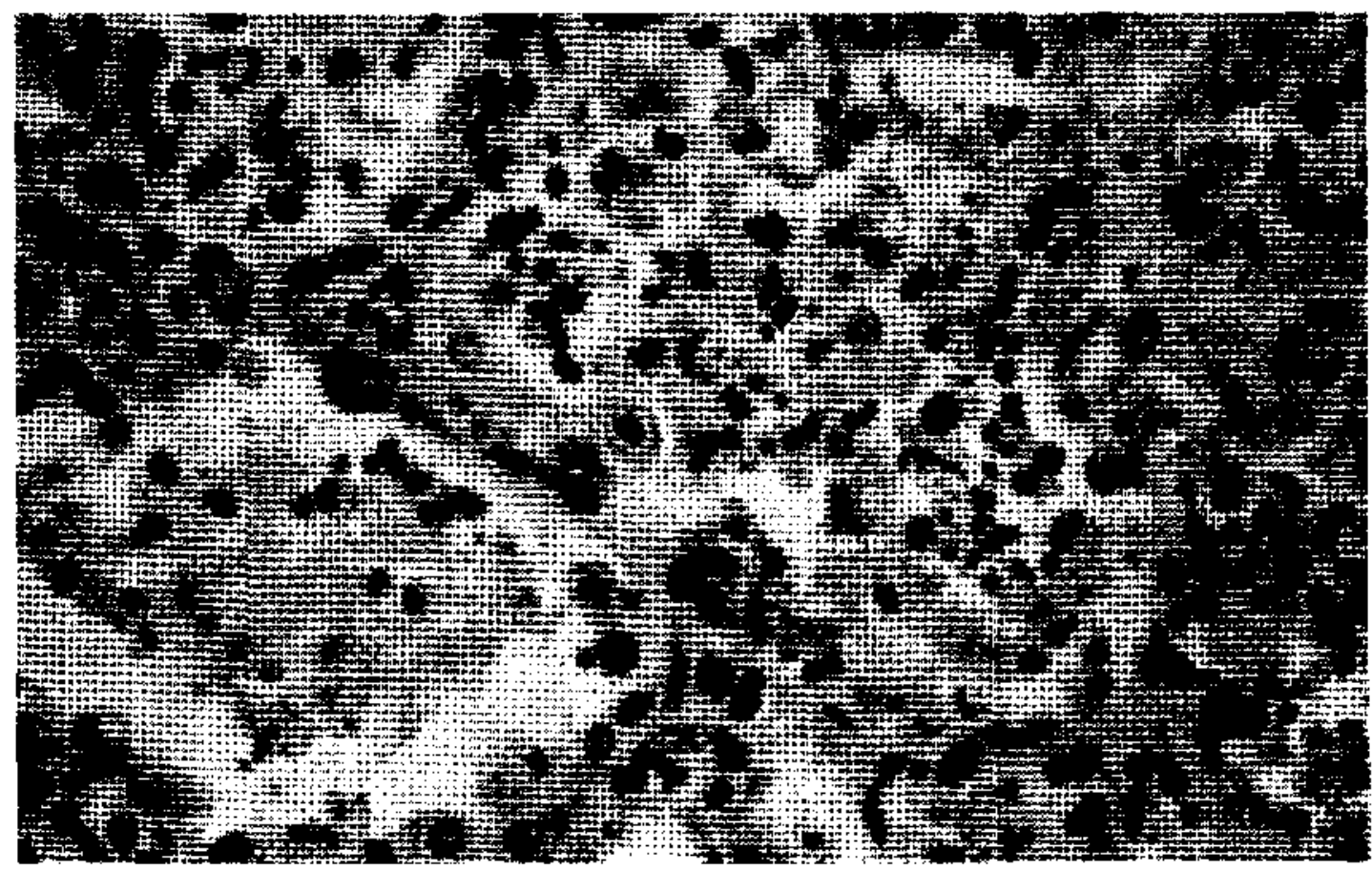

Figura 2: Microfotografía de tejido pulmonar en un paciente con neumanía por adenovirus. Tinción hematoxilina eosina. Aumento $130 \mathrm{X}$. Se observa bronconeumonía necrótica con abundante exudado intraalveolar, con inclusiones intranucleares y las células borrosas caracter isticas en el epitelio alveolar.

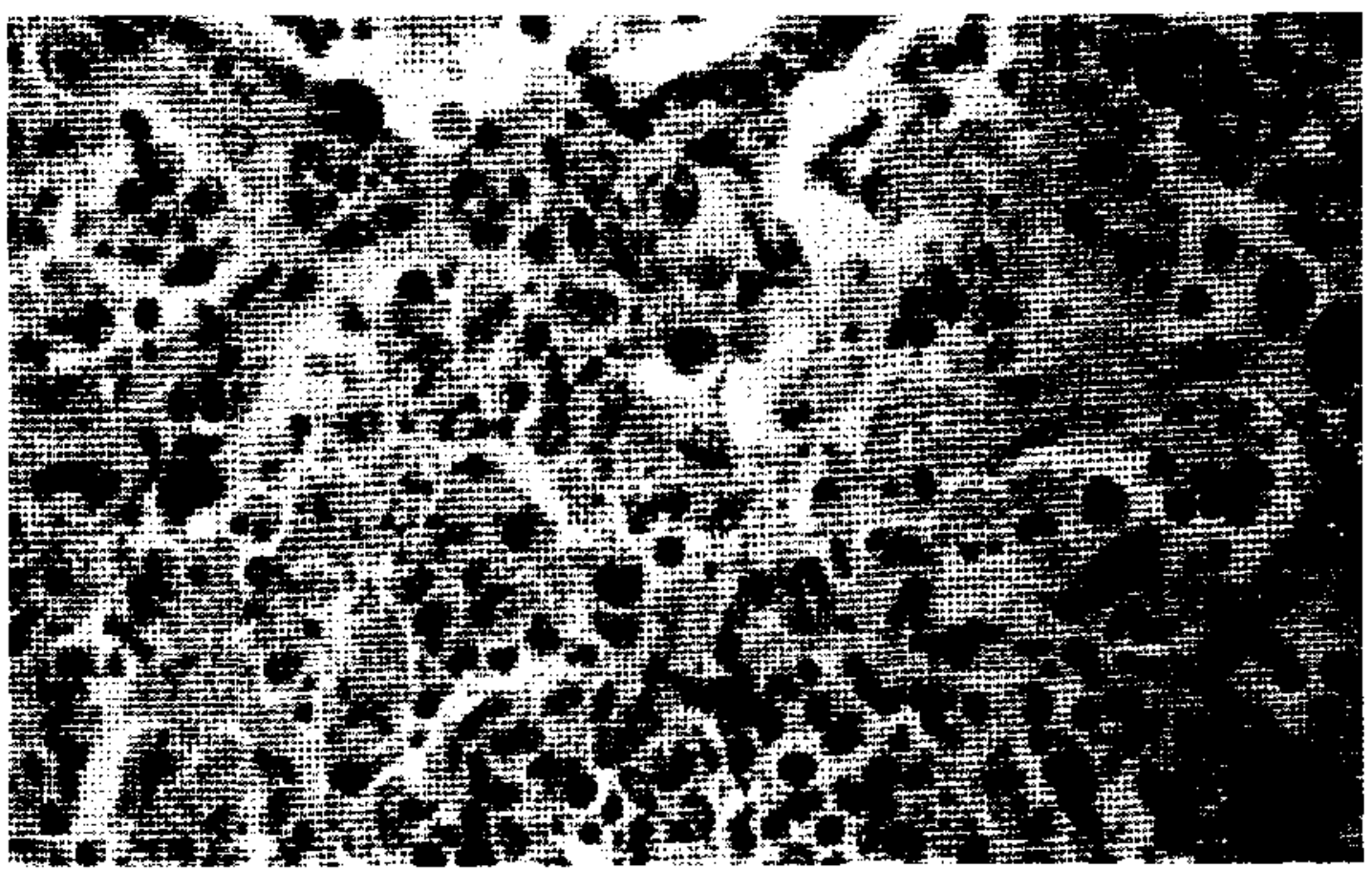

Figura 3: Microfotografia de tejido pulmonar en un paciente con neumonia por adenovirus. Tínción hematoxilina eosina. Aumento $130 \mathrm{X}$. Se observa bronconeumonía nectótica con abundante exudado intraalveolar, con inclu. siones nucleares y células borrosas. 
de tipo macrofágico, aisladas en el primero y abundantes en el segundo.

Los otros dos pacientes, los únicos de un mes de edad, desarrollaron una forma difusa de neumonitis interstjcial, con ensanchamiento de los tabiques alveolares por edema, congestión e infiltrado mononuclear, con escasos macrófagos alveolares (figura 4). Uno de ellos tenia exclusivamente evidencia de neumonitis; en el otro había, además, escasas lesiones bronquiolares características. En ambos la actividad regenerativa del epitelio respiratorio fue intensa $y$ exhibían escasas inciusiones características.

Patología extrapulmonar relacionada con la enfermedad viral. Uno de los lactantes con neumonitis intersticial desarrolló una encefalitis caracterizada por infiltrado mononuclear focal de predominio perivascular. El choque $y$ la hipoxia, como consecuencia de la grave patología pulmonar, dieron manifestaciones en diferentes parénquimas. En el hígado había lesiones consistentes en esteatosis difusa de predominio microvacuolar, extensa en todos los niros; eritrofagia ocasional, en dos; congestión, tumefacción turbia celular y necrosis de hepatocitos aislados.
En el cerebro se encontró edema e hiperemia en todos los casos y daño neuronal agudo, en seis. En los riñones había edema e hiperemia en todos los niños y necrosis tubular focal, en cuatro. La enfermedad viral se acompañó de fuerte disminución de los linfocitos del bazo, ganglios y timo en todos los casos examinados, asociada a reacción inmunoblástica en cinco.

Patología incidental. En un lactante menor se encontró displasia renal derecha y pielonefritis crónica inespecífica del mismo lado.

\section{DISCUSION}

Las muertes en niños hospitalizados con infecciones respiratorias bajas, debidas a $\mathrm{Ad}$ en 1988 , concuerdan con la mayor morbilidad por este virus detectada ese año y podrían corresponder con la eventual circulación en nuestra área, de alguno de los serotipos más agresi. $\operatorname{vos}^{1-4,9-10,12-17,24}$. Sin disponer de serotipificación de los Ad detectados, no es posible asegurarto tampoco descartar asociación con la epidemia de sarampión ocurrida en el país durante 1988 ,

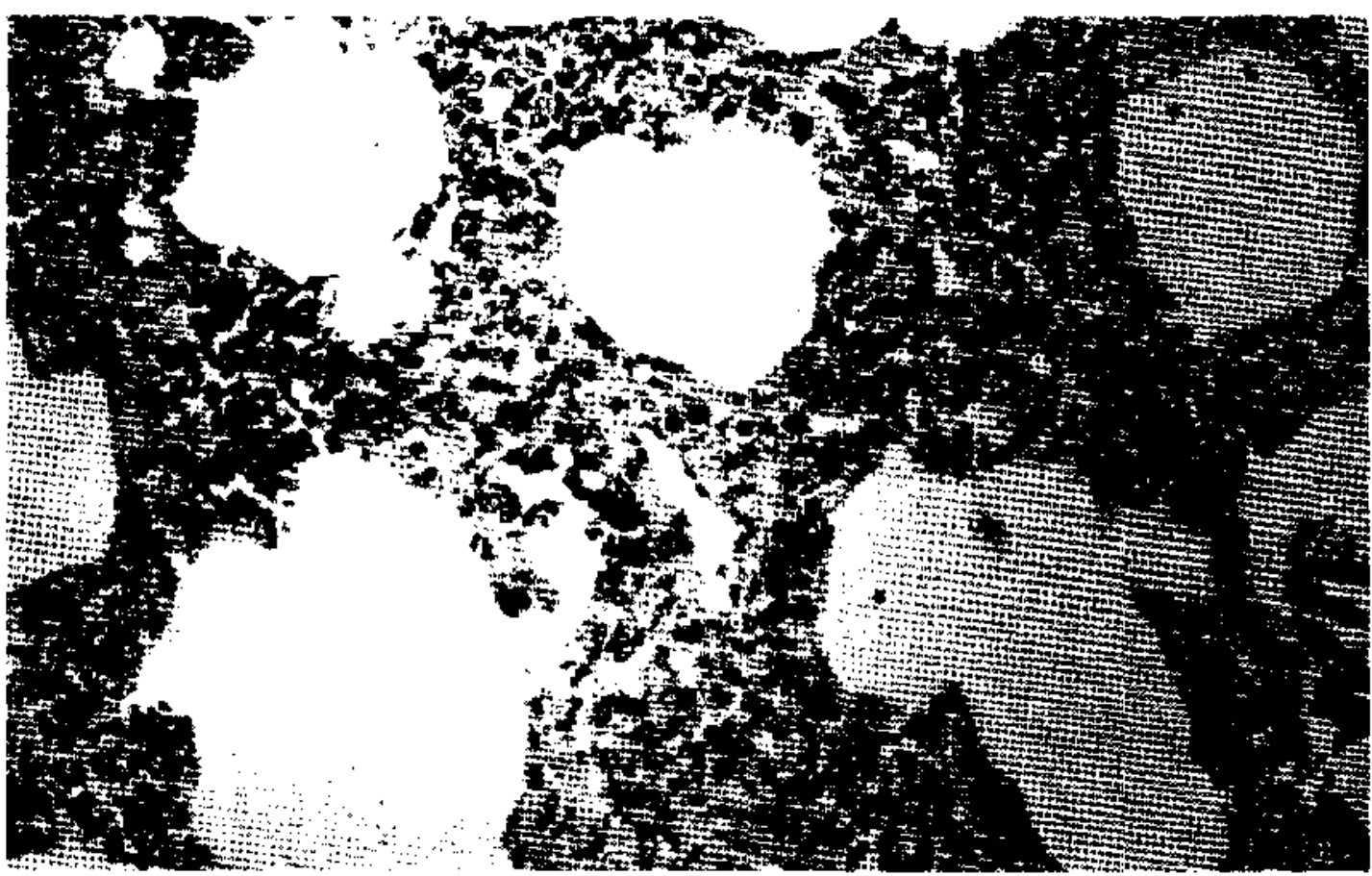

Figura 4: Microfotografja de tejido pulmonai en un paciente de un mes de edad con infección por adenovìrus. Tinción hematoxilina eosina. Aumento $70 \mathrm{X}$. Se observa neumonitis intersticial: tabiques alveolares ensanchados por congestión e infiltrado inflamatorio linfoplasmocitario; lumen alveolar libre. 
que pudiera haber contribuido a la agresividad observada ${ }^{1-4,9-10,32-20}$.

Como se muestra en los resultados, varios de nuestros casos presentaron uno o más de los factores señalados en la literatura como favorecedores de mayor gravedad, pero en lo relativo a desnutrición, ésta no fue relevante ${ }^{18-21}$

La fiebre alta mantenida, las manifestaciones clínicas y de laboratorio de compromiso multisistémico por Ad explican su frecuente confusión con infecciones bacterianas. El mayor daño del aparato respiratorio explica el desarrolto de insuficiencia respiratoria aguda global. que generalmente no cede con las medidas usuales $e$

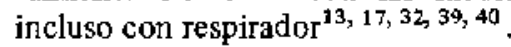

Todos nuestros pacientes tuvieron este tipo de presentación y evolución. El hemograma resultó poco orientador para el diagnóstico etiológico y en la mayoría de los casos se usaron antibióticos, incluso con esquemas agresivos, en aigún momento de la evolución, tratamiento que lógicamente resultó ineficaz por la causa viral de la enfermedad.

Los indices de gravedad más significativos fueron la existencia de leucopenta severa, VHS elevada $y$, en las radiografías de tórax, la rápida progresión y gran extensión de las lesiones pulmonares, concordante esta última con el desarro. llo de insuficiencia respiratoria aguda severa, que fue la causa de muerte en todos los enfermos a pesar del uso de respirador en catorce de ellos.

En todos los casos se comprobaron severas alteraciones anatomopatológicas, especialmente del aparato respiratorio, que explican el desenlace fatal.

Los hallazgos anatomopatológicos fueron los característicos de las formas graves de infección por Ad, con un componente pulmonar predominante manifestado por necrosis masiva del epitelio bronquial y bronquiolar y neumonía necrosante hemorrágica polilobar. En todos los casos con estas características, el hallazgo de inclusiones típicas, en gran número, fue la regla. La mayoria de los pacientes falleció en esta eta-

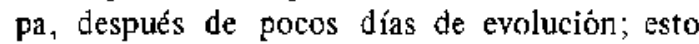
permitió ver elementos regenerativos del epitelio bronquial y bronquiolar, con metaplasia escamosa e hiperplasia severa en algunos pacientes. En forma excepcional se encontró focos de organización del exudado y del material necrótico bronquiolar con desarrollo de una bronquiolitis obliterativa que, como ya se señaló, es una de las secuelas que pueden quedar después de una
IRA por Ad. La forma de neumonitis intersticial pura fue relativamente rara en nuestro material. La presencia de células gigantes de tipo monocítico se observó en dos casos no relacionados con sarampión, pero simulando en uno de ellos la neumonitis de células gigantes que se ven en las formas de evolución anómala de esta enferme$\mathrm{dad}^{12}, 19-31,41-43$.

Los Ad suelen comprometer al SNC habiéndose descrito meningoencefalitis, como fue confirmado en un lactante de un mes de esta serie, que tuvo convulsiones, alteraciones quimicocitológicas del líquido cefalorraquídeo, como también encefalopatias y sindrome de Reye ${ }^{35-37}$.

El extenso compromiso pulmonar puede hacer que estos pacientes sufran precozmente choque y las consecuencias de hipoxia severa, que se manifiesta en los diversos parénquimas en forma de edema e hiperemia, esteatosis hepática, etc., explicando dichos hallazgos en los casos descritos.

Es posible que la demanda masiva de células linfoides a nivel de los extensos procesos infla. matorios en desarrollo explique la fuerte disminución de los elementos linfoides del bazo, ganglios y timo de estos pacientes y la reacción inmunoblástica de algunos de ellos.

Los casos presentados son un ejemplo de la severidad que suelen adquirir las infecciones por Ad y del manejo difícil y costoso que requieren; señalan, además, la importancia de contar en los hospitales con métodos que faciliten el diagnóstico rápido de la IRA ${ }^{44,45}$.

En el caso de los $A d$, si bien la técnica de mayor rendimiento es el aislamiento viral, Ja detección de antigenos, p. ej. por IFI, en muestras de secreciones nasofaringeas del paciente ofrece la ventaja de su rapidez, lo que permite adoptar a tiempo medidas epidemiológicas, como aislar precozmente los pacientes infectados, con el fin de evitar o disminuir la diseminación nosocomial del virus y con ello las graves consecuencias de este tipo de infección ${ }^{46,47}$.

\section{RESUMEN}

Se presentan dieciséis casos de niños que fallecieron por infección severa por Ad comprobada por estudios virológicos $(\mathrm{n}: 15) \mathrm{y}$, o, anatomopatológicos (n: 12). Se analizaron las características clinicas, de laboratorio, radiológicas y anatomopatológicas. Destaca una evolución clíni- 
ca severa, con manifestaciones multisistémicas, pero de predominio respiratorio, falleciendo todos los pacientes a causa de insuficiencia respiratoria aguda. Los resultados del hemograma $y$ VHS no fueron de ayuda para orientar hacia etiología viral o bacteriana de la afección. Las radiografias de tórax revelaron hiperinsuflación e imágenes de neumonitis y condensación, de rápida progresión. En el estudio anatomopatológico de diez casos se encontró bronquitis, bronquiolitis y neumonía necrosante con células con inclusiones intranucleares caracteristicas; en el de otros dos sólo neumonitis. En todos los pacientes se encontró esteatosis hepática y disminución linfocitaria a nivel del timo, bazo y ganglios linfáticos. Se subraya la importancia de disponer de métodos de diagnóstico rápido con el fin de evitar infecciones nosocomiales con este tipo de virus $y$, con ello, sus graves consecuencias.

(Palabras clave: neumonia viral, adenovirus.)

\section{AGRADECIMIENTOS}

A la sección Virología del Instituto de Salud Pública, al Laboratorio de Bacteriología, al Servicio de Radiología y a la Unidad de Enfermedades Broncopulmonares del Servicio de Pediatría del Hospital San Juan de Dios, por la colaboración prestada cn el estudio etiológico, radiológico $y$ clínico de estos pacientes.

\section{REFERENCIAS}

I. Wadel G.: Adenoviruses. En: Principles and Practice of Clinical Virology. Edit. Zuckerman A.J., Banatvala J.E. y Pattison J.R. 1987, John Wiley and Sons Ltd., London, 251.274.

2. Spencer M.J. y Cherry J.D.: Adenoviral infections. En: Textbook of Pediatric Infcctious Diseases. Edit. Feigin R.D. y Cherry J.D., 2a. ed., 1987, w. B. Saunders Company. Phuladelphia, 1968-1708.

3. Van der Veen $S$.: The role of adenoviruses in respiratory diseases. Am Rev Resp Dis 1963; 88: 167.180 .

4. Jackson E.E, y Huldoon R.L.: Viruses causing common respiralory infections in man. IV. Reoviruses and adenoviruses. J Infect Dis 1973: 128: 811-816.

5. Paisley J.W., Lauer B.A., Mc Intosh $K$. et at.: Pathogens associated with acute lower respiratory tract infection in young children. Pediatr Infect Dis $1984 ; 3 ; 14-19$.

6. Vicente $M$, Carrasco L., Burdach $R$, y Wh E.: Diagnóstico serológico de virus respiratorios en nifios. Libro de Publicaciones de la Primera Conferencia Internacional del Impacto de las Enfermodades Virales en Latinoamérica y Países del Caribe, Río de Janeiro, 1982; 2: 581-591.
7. Vicente $M$, Wis E, Carrasco L. et al: Detección viral en infecciones respiratorias agudas en niños hospitalizados. Estudio serológico. Enfer Respir Cir Torac, 1988: 4: 10-14.

B. Vicente $M$. Wu E., Carrasco L. et al.: Participación viral en las infecciones respiratorias agudas bajas del lactante. Rev Chil Pediatr, 1988; 59: 353-357.

9. Ruuskanen G., Meurman o. y Sarkkinen H: Adenoviral diseases in children: a study of 105 hospital cases. Pediatrics, 1985; 76: 79.82.

10. Edwards $K, M$, Thompson J., Poolini J. et al: Adenovirus infections in young children. Pediatrics, 1985;76: 420-424.

11. Larrañaga $C$., Vicente $M$., Wh $E$. et al.: Adenovirus en niños con infecciones respiratorias agudas bajas. Rev Chil Pediatr 1988; 59; 312-317.

12. Nahmizs A.J., Griffith $D, y$ Snitzer J.: Fatal pneumonia associated with adenovirus type ?. Amer J Dis Child 1967; $114: 36-41$.

13. Steen-Johnsen J., Orstavik J. y Atramadal A.: Severe illnesses due to adenovirus type 7 in chuldren. Acta Paediatr Scand 1969:58: 157-163.

14. Similä $S$., Rikorkala $O$. y Wasz-höckert $0 .:$ Type ? adenovirus pneumonia. J Pediatr 1971; 79: 605. 611.

15. James A.G., Lang W.R, Liang A.Y. et al.: Adenovirus type 21 bronchopneumoria in infants and young children. J Pediatr 1979;95: 530-533.

16. Leers W.D., Sorin M.K. v Kasupski G.J.: Lobar pneumonia associated with adenovirus type $?$. Can Med Assoc J 1981; 125 : 1003-1004.

17. Levy $Y$., Nitzan H., Berorab A. et al. Adenovirus type 3 infection with systemic manifestation in apparently nommal children. Isr J Med Sci 1986; 22: 774-778.

18. Sly P.D., Soto-Quiroz M.E., Londou L.T. et al. Factors predisposing to abnormal pulmonary function after adenovins type 7 preumonia. Arch Dis Child 1984: 59: 935-939.

19. Jen $K,-F$, Tai $Y$, Lin $Y$. ef al.: The role of adenovirus in the ctiology of infantile pneumonia and pneumonia complicating measies. Chin Med J (Eng]), 1962; 81: 141-146.

20. Warner J.O. y Marshall W.C.: Crippling hung disease after measles and adenovirus infection. Br J Dis Chest 1976; 70: 89-94.

21. Dagan R. Schurts R.H., Insel R.A. et al.: Severe diffuse adenovirus 7 a pneumonia in a child with combined inmunodeficiency: possible therapeutic effect of human serum globulin containing specific neutralizing antibody. Pediatr Infect Dis 1984; 3: 246.251 .

22. Chany $C$., Lepine $R$, Vinhl Lt. et al.: Severe and fatal pneumonia in infants and young childten associated with adenovirus infections. Am J Hyg 1958; 67: 367-378.

23. Deinhardt F., May R,D., Calhoun H. et al.: The isolation of adenovirus type 1 from a fatal case of viral "Pneumonitis". Arch Int Med 1958; 102: 816-819.

24. Chin-Hsien $r$.: Adenovirus pneumonia epidemic among Peking infants and preschool children in 1958. Chin Med I (Engl), 1960; 80: 331-339.

25. Wrigt H.T., Beckwith J.B. y Gwinn J.C.: A fatal case of inclusion body pneumonia in an infant 
with adenovirus type 3 . J Pediatr 1969; 65: 528 . 533.

26. Pinkerton H. y Carol S.: Fatal adenovirus pneumonia in infants. Am J Pathol 1971; 65: 543-548.

27. Becroft D.M.O.: Bronchiolitis obliterans, bronchiectasis and other sequelas of adenovirus type 21 infection in young children. J Clin Pathol 1971; 24: $72-82$.

28. Herber F.A., Wilkinson D., Burchak E. et al.; Adenovirus type 3 pneumonia causing lung damage in childhood. Can Med Assoc L 1977; 116: 274276.

29. Simila $S$., Linne $O$, Lanning $P$. et al.: Chronic lung damage caused by adenovirus type 7: a ten year follow-up study. Chest 1981; 80: 127-131.

30. Spigelblatt $L$. y Rosenfeld R.: Hiperlucent lung: long term complication of adenovirus type 7 pneumonia. Can Med Assoc J 1983; 128; 47-49.

31. Wu E., Flores M. $y$ Jerez E.: Pulmón hiperlúcido unilateral por adcnovirus. Rev Chil Pediatr 1990: 61: 41-44.

32. Sahler O.J.Z. $y$ wilfert C.M.: Fever and petechiae with adenovirus type 7 infection. Pediatrics 1974; 53: $233-235$.

33. Wu E., Avendaño L.F. y Grodo C.: Síndrome coqueluchoideo y adenovirus I. Rev Chil Pediatr $1975 ; 46: 34-46$.

34. Avendaño L.F. Wu E. y Grado C.: Síndrome coqueluchoideo y adenovirus II. Estudio de laboratorio. Rev Chil Pediatr 1975; 46: 307.

35. Kelsey D.S.: Adenovirus meningoencephalitis. Pediatrics 1978; 61: 291-293.

36. Kim K.S. y Godh R.S.: Acute encephalopathy in twins due to adenovirus type ? infection. Arch Neurol 1983; 40: 58-59.

37. Ladisch $S_{\text {, }}$ Lovejoy F.H., Herholzer J.C. et al.: Extrapulmonary manifestations of adenovirus type
7 pneumonia simulating Reye syndrome and the possible role of an adenovirus toxin. J Pediatr 1979; 95: 348-355.

38. Richmon S.J., Caul E.O., Dunn S.M. et al.: Aग outbreak of gastroenteritis in young children caused by adenoviruses. Lancet $1979 ; 1$ : 1178 1180.

39. Faden H. y Gallagher M.: Disseminated infection due to adenoyitus type 4 . Clin Pediatr 1980; 19: 427-429.

40. Hierholzer J.C., Torrence A.E. y Wright P.F. Generalized viral illness caused by an intermediate strain of adenovirus $(21 / \mathrm{H} 21+25)$. $J$ Infect Dis 1980; 141: 281-288.

41. Oshorne D. $\psi$ White P.: Radiology of epidemic adenovirus 21 infection of the lower respiratory tract infection in infants and young children. A J R 1979; 133: 379-400.

42. Wenman W.M., Paglakhan R.D., Reed M. et al.: Adenovirus bronchiolitis in Manitoba: epidemiologic, clinical and radiologic features. Chest 1982; 8I: $605-609$.

43. Chih-Chiuan $H$.: Adenovirus preumonia in infants and children. Pathologic studies of 40 cases. Chin Med J 1963; 82: 390-398.

44. Schmidt N.J.: Rapid viral diagnosis. Med Clin North Am 1983; 67: 953-972.

45. Richman D.D., Cleveland P.H., Redfield D.C. et al: Rapid viral diagnosis. I Infect Dis 1984; 149 : 298-310.

46. Harris D.J., Wulff H., Ray C.E, et al: Viruses and diseases ILI. An outbrcak of adenovirus type $7 \mathrm{a}$ in a children's home. Am J Epidemiol 1971; 93 : $399-402$.

47. Sirumbe R.C., Thompson M.A, Van Dyke R.B. et al:: Adenovirus type 7b iл a children's hospital. 1 Infect Dis 1983; 147: 814-819. 